\title{
The Dissolution of Language in Alzheimer's Disease
}

\author{
Andrew Kertesz, Julian Appell and Michael Fisman
}

\begin{abstract}
Language impairment in Alzheimer's disease has become an important clinical issue. It has been recognized for some time that the disease may begin with aphasia and even before frank aphasia develops, some of the earliest changes in a large number of individuals consist of impairment of word fluency and semantic access manifesting itself in word finding difficulty. The second major issue concerning language in Alzheimer's disease is that the cases which have early severe language impairment may represent a more progressive familial variety of disease as it has been suggested in the literature. This is still subject to controversy. Finally, it will be documented that the later stage of the disease shows language invariably impaired and goes through stages of dissolution that resemble anomic, transcortical sensory, Wernicke's and global aphasias. Accurate assessment of language may turn out to be one of the most reliable predictors of the stages of Alzheimer's disease and provides important insights into the cerebral organization of language, semantic access, relationship of semantic and episodic memory and the pathophysiology of the disease.
\end{abstract}

\begin{abstract}
RÉSUMÉ: La désintégration du langage dans la maladie d'Alzheimer. L'atteinte du langage dans la maladie d'Alzheimer est devenue un point de discussion important en clinique. C'est un fait reconnu, depuis quelque temps, que la maladie peut commencer par de l'aphasie et que, même avant le développement d'une aphasie franche, l'altération de la facilité de parole et de l'accès à la sémantique, se manifestant par de la difficulté à trouver les mots, sont parmi les changements les plus précoses chez un grand nombre de patients. Le second point de débat important concernant le langage dans la maladie d'Alzheimer est le fait que les cas qui ont un déficit précoce et sévère du langage peuvent représenter une forme familiale plus progressive de la maladie, telle que suggérée dans la littérature. Cette question est encore controversée. Pour terminer, nous établissons qu'en fin d'évolution de la maladie, il y a toujours atteinte du langage et la détérioration passe par des étapes qui ressemblent à certaines aphasies telles l'anomie, l'aphasie sensorielle transcorticale, l'aphasie de Wernicke et l'aphasie globale. Une évaluation précise du langage peut s'avérer être le factuer de prédiction le plus fiable des phases de la maladie d'Alzheimer et apporter des indices importants sur l'organisation cérébrale du langage, l'accès à la sémantique, la relation entre la mémoire sémantique et épisodique et la physiopathologie de la maladie d'Alzheimer.
\end{abstract}

Can. J. Neurol. Sci. 1986; 13:415-418

Language disturbance in Alzheimer's disease is now recognized as an important component of cognitive and clinical decline. Even the original case description of a 51 year old woman by Alzheimer included language impairment. ${ }^{1}$ What is then the relationship of language disturbance and Alzheimer's disease?

First of all, Alzheimer's disease, or a special variety of it if you are one of the splitters, may begin with aphasia. There are several individual case descriptions in the literature; one by Alajouanine $^{2}$ on the French composer, Ravel, another by Wechsler ${ }^{3}$ and a small recent series by Chawluk et al. ${ }^{4}$

Secondly, language impairment is invariably the case in Alzheimer patients who are ill enough to be hospitalized as we have shown in our study with Appell and Fisman. ${ }^{5}$

Thirdly, subtle language impairment is usually detectable early in the course of the illness if one uses measures of word fluency and complex verbal comprehension tasks, that overlap with tests of intelligence as shown by the exemplary work of Bayles et al. ${ }^{6}$ In other words, although memory followed by cognitive decline is still the common presentation of Alzheimer's disease, overt language disturbance is not far behind, and linguistic, especially semantic, components of cognition are affected early.

Finally, the measurement of language dissolution can be quantitated and the patient followed well into later stages where the usual intelligence tests cannot be applied anymore. This quantitation of the dissolution of language correlates with other behavioural and clinical staging and has the promise of relating to structural changes.

In our first study of language decline, we used the Western Aphasia Battery (WAB) ${ }^{7}$ in a population of hospitalized Alzheimer patients diagnosed according to the London Dementia 
Group criteria. ${ }^{5}$ The clinical diagnosis was supplemented by CT exclusion of other causes, in every case.

We used the WAB because it is a comprehensive and standardized aphasia examination and it is constructed specifically to study language deficits to minimize the effects of intelligence and education. ${ }^{8}$

From an initial target population of 41 , we found 25 testable patients. Table 1 shows the results of the language subtests. The lowest scoring subtest is clearly word fluency followed by a complex comprehension test, comprehension of sequential commands, which is similar to the Token Test, or Pierre Marie's three-paper test, and then by object naming. Information content of speech is significantly impaired, clearly dissociated from the relatively preserved spontaneous speech. The yes/no task and word recognition tasks have less semantic complexity and were done relatively better by our Alzheimer patients. Sentence completion and responsive speech were also easier for them.

Table 1: Aphasia Quotient and Oral Language Subtests: Mean Scores and Standard Deviations

\begin{tabular}{lcc}
\hline \hline & $\overline{\mathbf{X}}$ & SD \\
\hline Information & 4.3 & 2.6 \\
Fluency & 6.8 & 2.5 \\
Repetition & 5.7 & 3.5 \\
Comprehension total & 4.6 & 3.1 \\
Yes/no task & 6.3 & 2.8 \\
Word recognition & 5.3 & 4.1 \\
Sequential commands & 2.6 & 3.3 \\
Naming total & 3.6 & 3.1 \\
Object naming & 4.1 & 3.6 \\
Word fluency & 0.9 & 1.1 \\
Sentence completion & 4.6 & 3.9 \\
Responsive speech & 4.8 & 3.7 \\
$\quad$ Aphasia quotient & 50.1 & 27.0 \\
\hline
\end{tabular}

When the results were compared to stroke aphasics (Table 2) the significant differences were the higher fluency of Alzheimer patients in contrast to the better comprehension of stroke aphasics, even though these groups were well matched for severity as evidenced from their similar aphasia quotient (AQ). Naming and information content of speech was slightly more impaired in Alzheimer patients, and this is the feature that produces the peculiar, empty, circumlocutory speech of early Alzheimer which was recently further analyzed by Nicholas et al. ${ }^{9}$

The aphasic syndromes of Alzheimer patients were compared with stroke aphasics and Table 3 indicates the relative frequency of each aphasia type in the two groups and in the total aphasic population that also includes tumor and trauma. These results indicate a much higher (almost twice as high) incidence of Wernicke's, Mixed Transcortical, and Transcortical Sensory aphasics in Alzheimer patients and the conspicuous absence of Broca's or Transcortical Motor aphasias. Aphasia types appear to have a bimodal distribution in the Alzheimer group. By far, sensory aphasics or fluent aphasics appear to be in the majority but there is a substantial Global group among Alzheimer patients who are the most severely affected.

The extent of language impairment has correlated with the duration of illness as we approximated it by using the length of hospitalization (Table 4). On the other hand, language impairment and age did not correlate as in some other studies which found aphasia and early onset associated. ${ }^{10}$

Reading and writing subtests showed more severe involvement than oral language (Table 5). Reading comprehension is low even in the mildly affected patients, though they can often read aloud (Transcortical alexia). Writing may be one of the first functions to suffer as one of the patients who had intact oral language complained: "I can't remember how the Q goes." Praxis was similarly affected to oral language.

We have followed 29 Alzheimer patients with language and performance tests for a year or more. Twenty from the original hospitalized sample and 9 from newly diagnosed Alzheimer

Table 2: Alzheimer and Stroke Aphasics: Difference Between Means of Oral Language Subtests

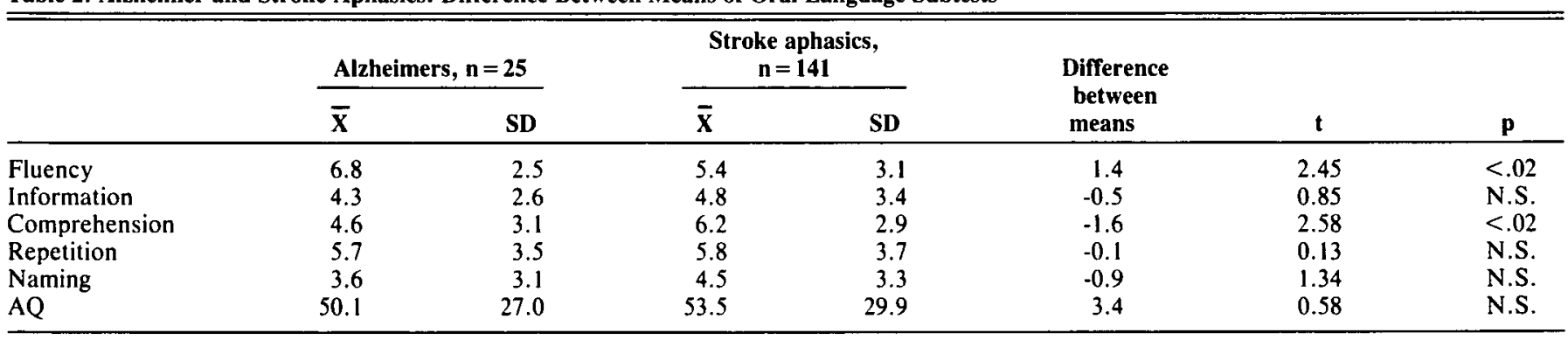

Table 3: Percentage Frequency of Different Aphasic Syndromes in Alzheimer Patients, Stroke Patients, and All Aphasic Types

\begin{tabular}{lrrr}
\hline \hline & $\begin{array}{c}\text { Alzheimer patients } \\
\mathbf{n = 2 5}\end{array}$ & $\begin{array}{c}\text { Stroke patients } \\
\mathbf{n = 1 4 1}\end{array}$ & $\begin{array}{c}\text { All aphasic types } \\
\mathbf{n}=\mathbf{3 6 5}\end{array}$ \\
\hline Global & 24 & 14 & 16 \\
Broca's & 0 & 19 & 17 \\
Isolation & 8 & 2 & 3 \\
Wernicke's & 28 & 11 & 5 \\
Transcortical motor & 0 & 5 & 9 \\
Transcortical sensory & 16 & 9 & 7 \\
Conduction & 4 & 31 & 9 \\
Anomic & 20 & 29 & 2 \\
\hline
\end{tabular}




\begin{tabular}{lcc}
\hline Table 4: Language Variables Correlating Significantly With N Days \\
\hline \hline & $\mathbf{r}$ & $\mathbf{p}$ \\
\hline AQ & -.444 & .030 \\
Comprehension & -.434 & .030 \\
Repetition & -.395 & .050 \\
Information & -.434 & .030 \\
Fluency & -.448 & .030 \\
Auditory verbal & & \\
$\quad$ comprehension & -.560 & .004 \\
\hline
\end{tabular}

Table 5: Reading, Writing, Praxis, Construction, and PO: Mean Scores and Standard Deviations of Alzheimer Patients $(n=20)$

\begin{tabular}{lccccc}
\hline \hline & Reading & Writing & Praxis & Construction & PQ \\
\hline$\overline{\bar{X}}$ & 3.1 & 2.3 & 4.2 & 2.1 & 28.8 \\
SD & 3.2 & 2.7 & 3.4 & 2.3 & 27.9 \\
\hline
\end{tabular}

\begin{tabular}{|c|c|c|c|c|c|c|}
\hline & \multicolumn{2}{|c|}{ Initial } & \multicolumn{2}{|c|}{ Follow-up } & \multirow[b]{2}{*}{$t$} & \multirow[b]{2}{*}{$\mathbf{p}$} \\
\hline & $\overline{\mathbf{x}}$ & SD & $\vec{x}$ & SD & & \\
\hline Information & 4.1 & (2.8) & 3.2 & (3.3) & 2.00 & NS \\
\hline Fluency & 6.6 & (2.5) & 5.8 & (3.1) & 1.48 & NS \\
\hline Repetition & 5.4 & (3.7) & 4.1 & (3.7) & 3.29 & $<.01$ \\
\hline Comprehension & 4.6 & (3.2) & 3.5 & (3.6) & 3.46 & $<.01$ \\
\hline Yes-no task & 6.2 & (3.1) & 4.6 & (3.6) & 3.46 & $<.01$ \\
\hline Word recognition & 5.5 & (4.3) & 3.8 & (4.4) & 3.65 & $<.01$ \\
\hline Sequential commands & 2.7 & (3.3) & 2.3 & $(3.5)$ & 0.72 & NS \\
\hline Naming & 3.6 & (3.2) & 2.8 & $(3.0)$ & 3.57 & $<.01$ \\
\hline Object naming & 4.1 & (3.8) & 3.2 & (3.5) & 3.31 & $<.01$ \\
\hline Word fluency & 0.9 & (1.1) & 0.8 & (1.3) & 0.50 & NS \\
\hline Sentence completion & 4.5 & (4.1) & 3.6 & (4.2) & 1.44 & NS \\
\hline Responsive speech & 4.6 & (3.7) & 4.0 & (4.3) & 1.45 & NS \\
\hline Aphasia Quotient & 48.4 & (28.4) & 38.9 & (31.7) & 3.84 & $<.001$ \\
\hline
\end{tabular}

Table 7: Reading, writing, praxis, construction and performance quotient: comparison of initial and follow-up means and standard deviations.

\begin{tabular}{lcccccc}
\hline \hline & $\overline{\mathbf{x}}$ & SD & $\overline{\mathbf{x}}$ & SD & \multicolumn{1}{c}{$\mathbf{t}$} & $\mathbf{p}$ \\
\hline Reading & 3.1 & $(3.2)$ & 2.4 & $(3.5)$ & 1.66 & NS \\
Writing & 2.2 & $(2.7)$ & 1.6 & $(2.8)$ & 1.48 & NS \\
Praxis & 4.3 & $(3.4)$ & 3.4 & $(4.2)$ & 1.68 & NS \\
Construction & 2.5 & $(2.8)$ & 2.0 & $(2.6)$ & 2.48 & $<.05$ \\
$\quad$ Drawing & 0.2 & $(0.2)$ & 0.1 & $(0.3)$ & 1.34 & NS \\
Block design & 0.1 & $(0.2)$ & 0.1 & $(0.2)$ & 1.00 & NS \\
$\quad$ Calculation & 3.8 & $(4.2)$ & 2.6 & $(3.4)$ & 3.77 & $<.01$ \\
Performance quotient & 30.9 & $(29.4)$ & 24.2 & $(31.7)$ & 2.51 & $<.05$ \\
\hline
\end{tabular}

\begin{tabular}{llr}
\hline Table 8: Patterns of Early Deterioration $(\mathbf{n}=\mathbf{3 3})$ & \\
\hline \hline 1. Mainly memory, lesser cognitive loss, mild language & \\
impairment & $(11)$ \\
2. Mainly cognitive, lesser memory loss, mild language & $(8)$ \\
impairment & $(5)$ \\
3. Mainly cognitive, lesser memory, intact language & $(4)$ \\
4. Primarily aphasia, interfering with other tests & $(1)$ \\
5. Only memory decline, intact language and cognition & (1) \\
6. Mainly memory and cognitive loss, intact language & \\
7. Evenly distributed decline &
\end{tabular}

patients satisfy DSMIII criteria and a negative CT. The results are summarized in Table 6 . The group showed a significant worsening of language disturbance, even though there were three patients who were stable and two who even showed some improvement in their scores. Certain subtests which were low to begin with such as word fluency, declined little, indicating a "floor effect"' but previously moderately impaired variables, such as repetition and yes/no comprehension showed a more definite decline bringing the total score or aphasia quotient down significantly. The decline of nonverbal subtests (Table 7) was significant in construction and calculation subtests and in the total performance quotient. Some non-oral functions were so low at the initial examination that the decline was relatively small due to a floor effect.

The pattern of decline was also examined in 33 ambulatory patients who had language, memory and intelligence testing at the initial diagnosis. This does not necessarily reflect the presenting symptomatology which is quite difficult to define and standardize as it depends entirely on history from relatives. The majority of these ambulatory patients have some memory loss before they, or their relatives seek help. By the time they are seen in the clinic, there is always some memory or cognitive impairment but language impairment is also present in the majority. There were significant exceptions to this however. We took the WAB and used the cut-off score of 93.8 as the definition of intact language function. Intact language as measured on a specifically designed language test, is different from verbal intelligence which was often affected in these patients. This distinction of verbal intelligence from language is often neglected by investigators. Memory deficits were measured by the Wechsler Memory Scale (WMS) and cognition by the performance quotient of the revised Wechsler Adult Intelligence Scale (WAIS-R).

Nine out of 33 patients had intact language on the WAB. The patterns that were found are tabulated (Table 8). The most common problem was loss of memory and cognition with relatively preserved but mildly impaired language. In the second most common pattern nonverbal cognition of performance was affected most along with memory and only mild language impairment. Other relatively common patterns were cognitive and memory impairment and intact language or the opposite present with predominantly language impairment. One of these patients was a Broca's aphasic, an exception to the general Alzheimer's population worthy of special scrutiny. Quite possibly the patient has Pick's disease with specific frontal lobe involvement. Other less common initial patterns were pure memory loss, and a rather evenly, mild distribution of impairment.

We were the first to report the overall severity of language loss and its decline in an Alzheimer population with a standardized aphasia test, as well as the information content in their speech, which is equivalent to functional communication. Language is relatively little impaired initially, allowing us to measure memory and intelligence.However, when comprehension disturbance, paraphasic output, severe anomia, and finally mutism develops, the severe impairment of communication precludes memory or intelligence testing, and the quantitation of language loss becomes an important measure of the decline itself.

The specific pattern of language loss in Alzheimer's disease with heavy emphasis on semantic operations, verbal memory and cognitive performance provides a cue about the organiza- 
tion of language and memory in the brain. Pathological studies of Alzheimer patients show neuronal loss in the phylogenetically older sections of the brain subserving memory and the tertiary association areas, subserving semantic operations and nonverbal cognition. This is in contrast to the perisylvian focality of stroke lesions that produce the loss of syntax and phonology and the accompanying aphasic syndromes.

The language disturbance in Alzheimer's disease reveals that semantic and cognitive operations can be impaired independently from phonemic and syntactic functions indicating the specificity of the latter for language. Semantic operations are more widely distributed in the brain with more extensive limbic connections and overlap with memory, verbal intelligence, and nonverbal cognition to a greater extent, than the focally organized language functions in the left perisylvian cortex that is initially less affected in Alzheimer's disease.

\section{Conclusions}

1. All hospitalized Alzheimer patients have some language deficit.

2. Most, but not all, patients have language impairment when initially seen as outpatients.

3. Memory and cognitive decline is more significant initially than language impairment.

4. Transcortical, Sensory and Wernicke's aphasias occur in higher proportion in Alzheimer than stroke aphasics.

5. Broca's and Transcortical aphasias are rarely seen in Alzheimer's disease.

6. Aphasia is the presenting feature in some Alzheimer patients.

7. Alzheimer language deficit is charcterized by higher fluency and lower comprehension when compared to stroke population matched in severity.
8. Syntax and phonology are relatively preserved in contrast to the semantic impairment.

9. The progression of language impairment is characteristic: Anomic (Empty) $\rightarrow$ Transcortical Sensory $\rightarrow$

Wernicke's $\rightarrow$ Global.

10. Alzheimer patients with Global (poor comprehension and output) have syllabic preservation, shouting, laughter that is distinctive from stroke patients.

11. Reading and writing are relatively more impaired than oral language.

12. Apraxia is similar in extent to language impairment.

\section{REFERENCES}

1. Alzheimer A. On a peculiar disease of the cerebral cortex. Allg Z Psychiat 1907; 64: 146.

2. Alajouanine TH. Verbal realization in aphasia. Brain, 1956; 79: $1-28$.

3. Wechsler AF. Presenile dementia presenting as dementia. J Neurol Neurosurg Psychiatry 1977; 40: 303-305.

4. Chawluk JB, Mesulam MM, Hurtig $\mathbf{H}$, et al. Slowly progressive aphasia without generalized aphasia: studies with positron emission tomography. Ann Neurol 1986; 19(1): 68-74.

5. Appell J, Kertesz A, Fisman M. A study of language functioning in Alzheimer patients. Br Lang, 1982; 17: 73-91.

6. Bayles KA, Tomoeda CK, Kaszniak AW, et al. Verbal perserveration of dementia patients. Br Lang 1985; 25(1): 102-116.

7. Kertesz A. The Western Aphasia Battery. New York. Grune \& Stratton, 1982.

8. Kertesz A. Aphasia and Associated Disorders. New York. Grune \& Stratton, 1979.

9. Nicholas M, Obler LK, Albert ML et al. Empty speech in Alzheimer's disease and fluent aphasia. J Speech Hearing Res 1985; 28 : 405-410.

10. Seltzer B, Sherwin I. A comparison of clinical features in earlyand late-onset primary degenerative dementia. Arch Neurol 1983; 40: 143-146. 